\title{
CHRONIC PRESSURE ULCERS IN A CASE OF SPASTIC PARAPLEGIA FOLLOWING DIVER'S DISEASE (DECOMPRESSION SICKNESS), THE NEED FOR INTEDISCIPLINARY MANAGEMENT
}

Ilias Karagiannakis ${ }^{1}$, A. Kontaxakis ${ }^{1}$, E. Diamantidis ${ }^{1}$, A-M. Nella ${ }^{1}$, G. Stourgis-Venetas ${ }^{1}$, E. Gamatsi², Evangelia Livana ${ }^{3}$, A. Aggelis ${ }^{4}$, P. Marouli ${ }^{4}$, D. Kagiouli ${ }^{1}$, S. Fotaki ${ }^{1}$ \& C-A Rapidi ${ }^{1}$.

Department of Physical Medicine and Rehabilitation, General Hospital of Athens Gennimatas

. Department of Plastic Surgery, General Hospital of Athens Gennimatas

3. Department of Physiotherapy G.H.A., Gennimatas

4. Department of Occupational Therapy G.H.A. Gennimatas

Introduction: Treatment of chronic recurrent pressure ulcers is a challenge for the rehabilitation team. Their prevalence in persons living in the community is as high as $17-32 \%{ }^{1-3}$, with higher impact 10 years after injury and their impact on quality of life is significant ${ }^{4}$.

Purpose: Study of the need for interdisciplinary therapeutic treatment in a case of chronic recurring pressure ulcers at a rehabilitation department in a general hospital.

Method: case report presentation

Results: : A 42-year-old patient with incomplete spastic paraplegia neurological level T7 (AIS B), following diver's disease, twelve years post injury. Patient presented pressure ulcers of grade IV over both sciatic curvatures for the last five years. During that time, the patient has undergone multiple treatments (wound dressings, surgical debridement, hyperbaric oxygen chamber sessions, antibiotic therapy) with partial healing of the ulcers. Osteomyelitis had been diagnosed and the patient was hospitalized in internal medicine department for proper therapy. Eighteen months post hospitalization the patient was admitted in PRM department with recurrent pressure ulcers.

Patient was assessed and treated for: Malnutrition, lower limb spasticity (dantrolene, and botulin toxin A for regional spasticity of both iliopsoas), urinary incontinence (oxybutynin, and regular program of bladder emptying with intermittent selfcatheterizations). He was also assessed and followed-up by psychologist. CT, MRI, bone scintigraphy and ulcer fistulography, were used for pressure ulcers imaging. Ulcers were surgically treated with direct wound closure from a plastic surgeon
The patient was discharged after 75 days of treatment in the PRM department with complete healing of all pressure ulcers, with decreased spasticity, improved urinary, nutritional and psychiatric disorders. Special patient education was provided for pressure ulcers prevention by all members of rehabilitation team (physicians, nurses, occupational therapists, and physiotherapists). One year after discharge, during follow up, patient remains free of pressure ulcers.

Discussion and Conclusion: Pressure ulcers in patients with $\mathrm{SCl}$ present a significant cost for the health care system ${ }^{5}$ and often lead to recurrent hospitalizations, multiple surgeries, and impact quality of life ${ }^{4}$. After 5 years of unsuccessful mainly home-based conservative treatment, hospitalization in the PRM department with interdisciplinary approach of the rehabilitation team, led to complete ulcer's healing.

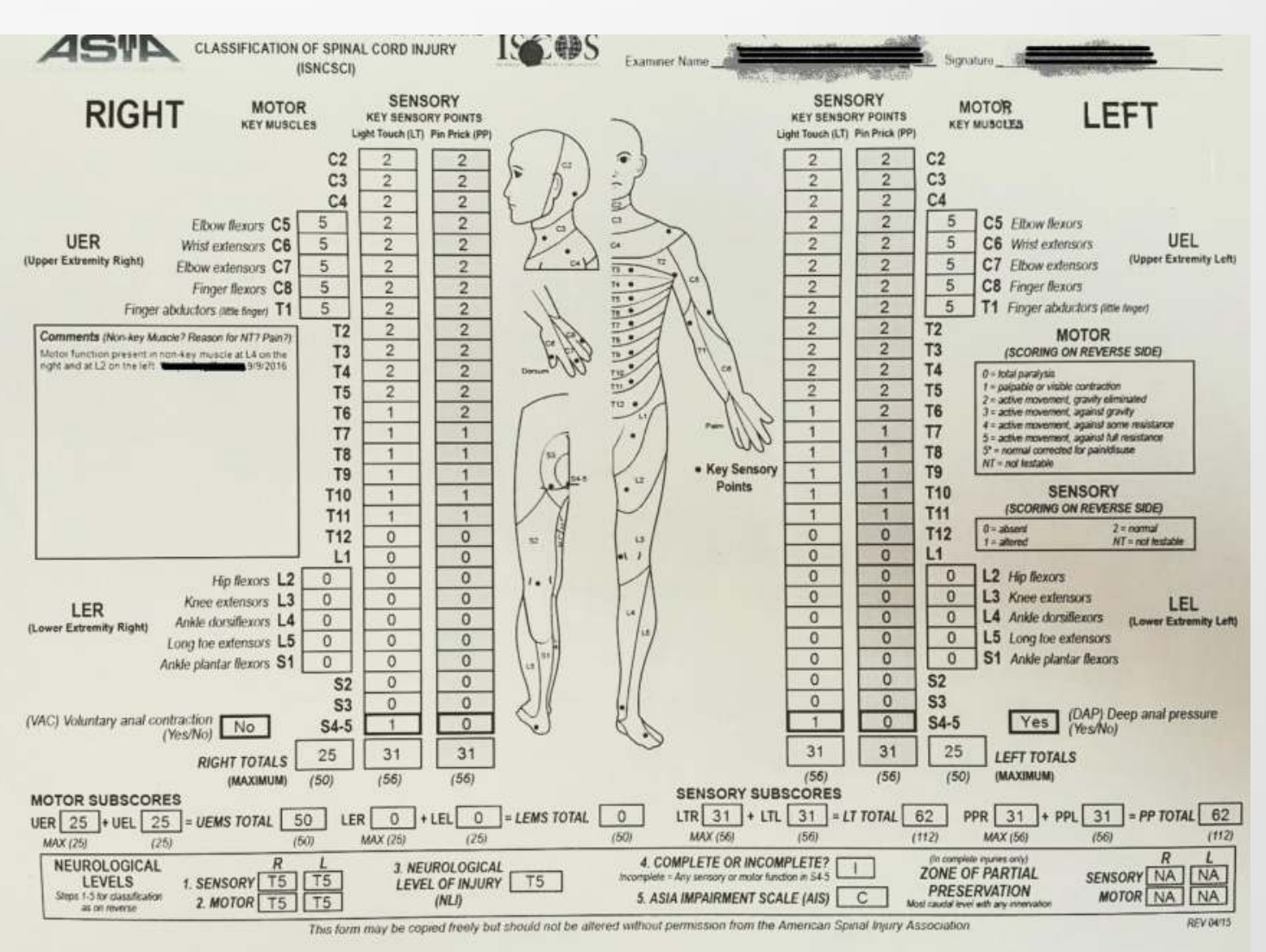

\section{References}

Gélis A, Dupeyron A, Legros P, Benaïm C, Pelissier J, Fattal C. Pressure ulcer risk factors in persons with SCl: Part I: Acute and bilitation stages. Spinal Cord. 2009;47(2):99-107. doi:10.1038/sc.2008.107.

Groah SL, Schladen M, Pineda CG, Hsieh C-HJ. Prevention of Pressure Ulcers Among People With Spinal Cord Injury: A Systematic Review. PM R. 2015;7(6):613-636. doi:10.1016/j.pmrj.2014.11.014.

3. Marin J, Nixon J, Gorecki C. A systematic review of risk factors for the development and recurrence of pressure ulcers in people with splnal cord injuries. Spinal Cord. 2013;51(7):522-527. doi:10.1038/sc.2013.29.

4. Hitzig SL, Balioussis C, Nussbaum E, McGillivray CF, Catharine Craven B, Noreau L. Identifying and classifying quality-of-life tools for assessing pressure ulcers after spinal cord injury. J Spinal Cord Med. 2013;36(6):600-615. doi:10.1179/2045772313Y.0000000129.

5. Regan MA, Teasell RW, Wolfe DL, Keast D, Mortenson WB, Aubut JAL. A Systematic Review of Therapeutic Interventions for Pressure Ulcers After Spinal Cord Injury. Arch Phys Med Rehabil. 2009;90(2):213-231. doi:10.1016/j.apmr.2008.08.212. 